\title{
LANDSAT-8 OPERATIONAL LAND IMAGER ON-ORBIT RADIOMETRIC CALIBRATION
}

\author{
Brian L. Markham ${ }^{1}$, Julia A. Barsi ${ }^{2}$ \\ ${ }^{1}$ Biospheric Sciences Lab, Code 618, NASA/GSFC, Greenbelt, MD 20771, \\ ${ }^{2}$ Biospheric Sciences Lab, Code 618, SSAI/GSFC, Greenbelt, MD 20771
}

\begin{abstract}
The Operational Land Imager (OLI), the VIS/NIR/SWIR sensor on the Landsat- 8 has been successfully acquiring Earth Imagery for more than four years. The OLI incorporates two on-board radiometric calibration systems, one diffuser based and one lamp based, each with multiple sources. For each system one source is treated as primary and used frequently and the other source(s) are used less frequently to assist in tracking any degradation in the primary sources. In addition, via a spacecraft maneuver, the OLI instrument views the moon once a lunar cycle $(\sim 29$ days). The integrated lunar irradiances from these acquisitions are compared to the output of a lunar irradiance model. The results from all these techniques, combined with cross calibrations with other sensors and ground based vicarious measurements are used to monitor the OLI's stability and correct for any changes observed. To date, the various techniques have other detected significant changes in the shortest wavelength OLI band centered at $443 \mathrm{~nm}$ and these are currently being adjusted in the operational processing.
\end{abstract}

Index Terms - Landsat, radiometric calibration

\section{INTRODUCTION}

Landsat-8 was launched on February 11, 2013, began operational data collection at the end of May 2013 and has been successfully operating since. The instrument complement includes the Operational Land Imager (OLI), (Figure 1) which covers the Visible to SWIR region in 9 spectral bands (Table 1). In addition to the historical spectral bands on previous Landsats, a shorter wavelength coastal aerosol $443 \mathrm{~nm}$ band and a cirrus detection band at $1375 \mathrm{~nm}$ were added.

A key feature of the OLI design is multiple onboard calibration systems. A pair of stim lamp assemblies each with six lamps (three lamps on side $\mathrm{A}$ and three on side $\mathrm{B}$ electronics) is located near the entrance aperture and provides illumination of the full focal plane. A lamp in each assembly is wired in series with a lamp in the other assembly. Any one pair can be illuminated at a time. A pair designated "working" are used daily; a pair designated "backup" are used once every two weeks and a pair designated "pristine" are used every six months. Two solar diffusers are located in the solar diffuser wheel (Figure 1). When one is rotated into position and the spacecraft maneuvered so that the sun is centered in the diffuser port, light reflects off the diffuser into the OLI optics. The "working" diffuser is used about every 8 days and the "pristine" diffuser is used every six months.

The final built-in calibration capability is a routine spacecraft maneuver to view the moon with the OLI instrument. During this maneuver, each detector focal plane module completely images the moon via a series of scans. The lunar images are integrated to produce a lunar irradiance, which is then compared to the ROLO-based lunar irradiance model for the particular observation conditions [1].

Table 1. Landsat-8 OLI spectral bands

\begin{tabular}{|c|c|c|c|}
\hline $\begin{array}{c}\text { Band } \\
\#\end{array}$ & Band Name & $\begin{array}{l}\text { Lower } \\
\text { Band } \\
\text { Edge } \\
(\mathrm{nm})\end{array}$ & $\begin{array}{l}\text { Upper } \\
\text { Band } \\
\text { Edge } \\
(\mathrm{nm})\end{array}$ \\
\hline 1 & $\begin{array}{c}\text { Coastal } \\
\text { Aerosol (CA) }\end{array}$ & 435.0 & 451.0 \\
\hline 2 & Blue & 452.0 & 512.1 \\
\hline 3 & Green & 532.7 & 590.1 \\
\hline 4 & Red & 635.9 & 673.3 \\
\hline 5 & $\begin{array}{l}\text { Near Infrared } \\
\text { (NIR) }\end{array}$ & 850.5 & 878.8 \\
\hline 6 & $\begin{array}{l}\text { Short Wave } \\
\text { Infrared -1 } \\
\text { (SWIR-1) }\end{array}$ & 1566.5 & 1651.2 \\
\hline 7 & $\begin{array}{l}\text { Short Wave } \\
\text { Infrared -2 } \\
\text { (SWIR-2) }\end{array}$ & 2107.4 & 2294.1 \\
\hline 8 & $\begin{array}{l}\text { Panchromatic } \\
\text { (Pan) }\end{array}$ & 503.3 & 675.7 \\
\hline 9 & Cirrus & 1363.2 & 1383.6 \\
\hline
\end{tabular}




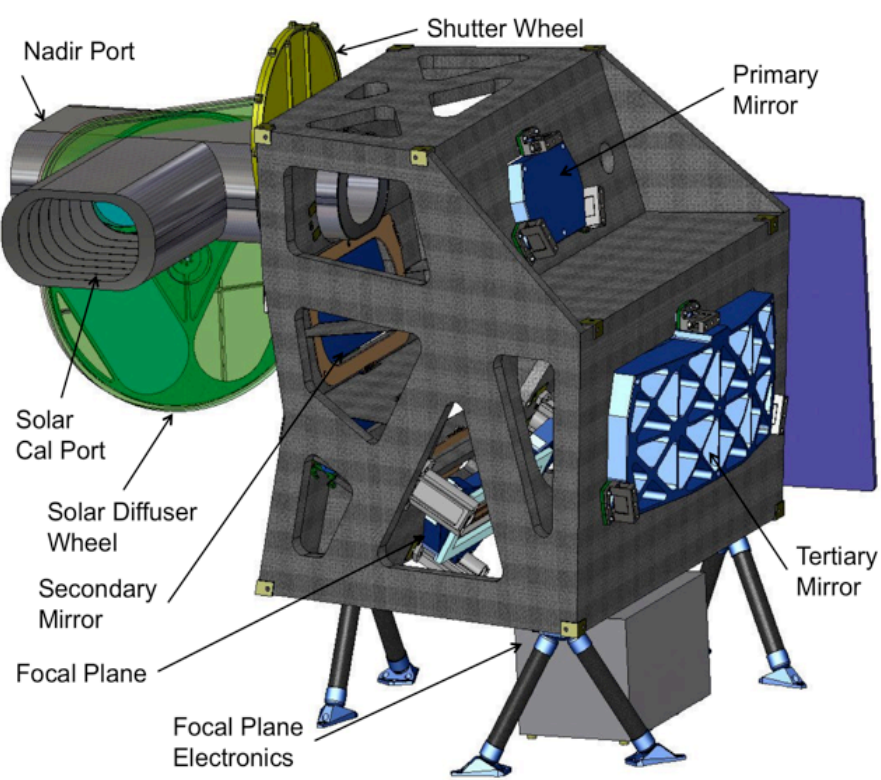

Figure 1. OLI (Ball Aerospace Drawing)

\section{METHODS}

The data from each of the calibrators are processed within the Landsat Image Assessment System. The results for each calibrator in terms of detector-by-detector responsivity are averaged across all those detectors. For trending purposes all results are normalized to an early acquisition, about 75 days after launch. Trends are compared between techniques to decipher instrument responsivity changes versus calibrator artifacts.

\section{RESULTS}

Representative band results as of May 2017 are shown in Figure 2-5.

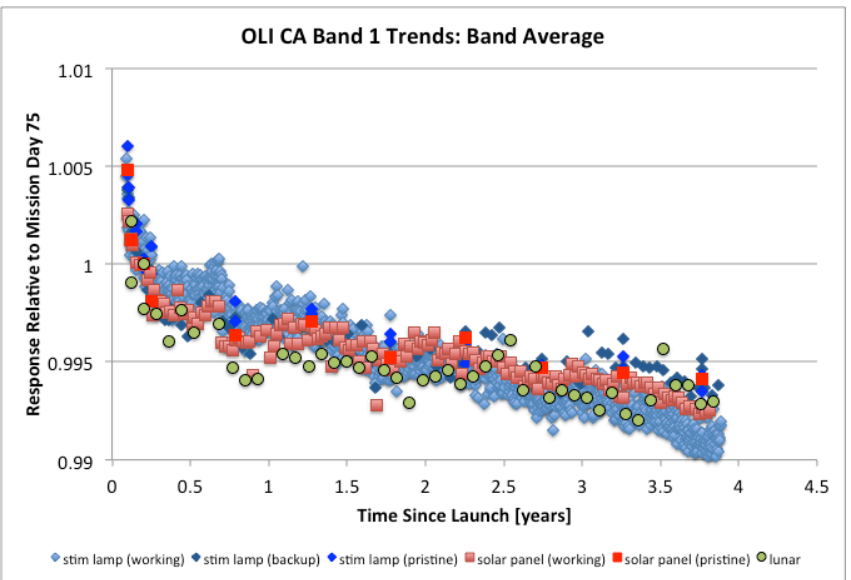

Figure 2. Coastal Aerosol band responsivity trends

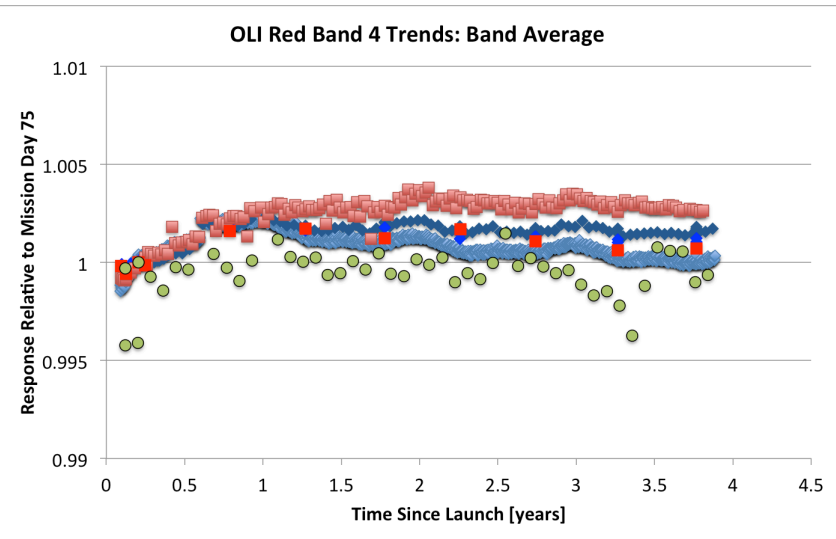

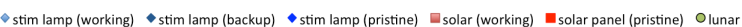

Figure 3. Red Band Responsivity Trends

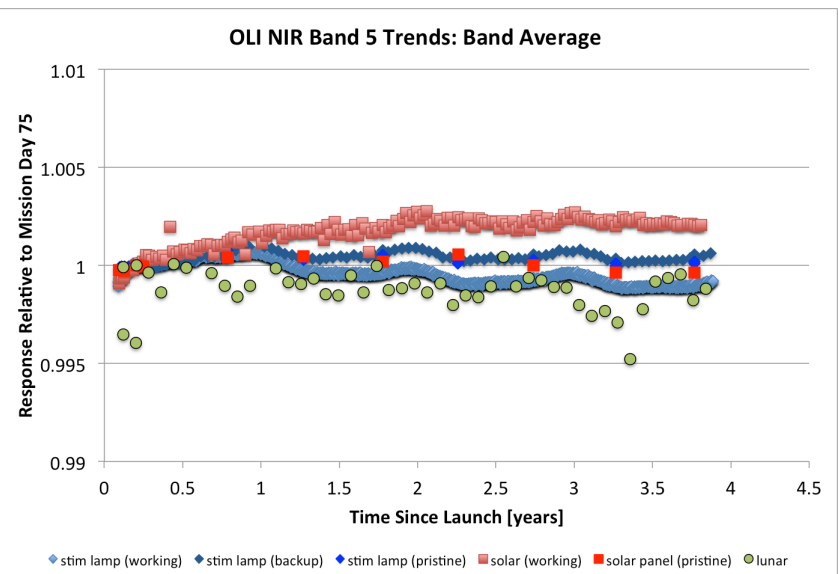

Figure 4. NIR Band Responsivity Trends

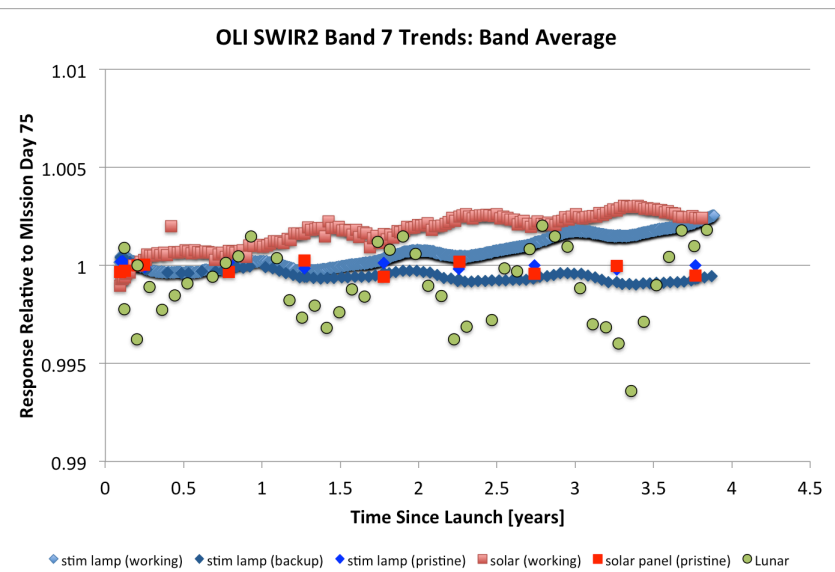

Figure 5. SWIR-2 Band Responsivity Trends

Several instrument and calibrator changes are evident in the plots. Some degradation in the working stim lamp is apparent, with the output decreasing in the shortest wavelength and increasing in the longest wavelength. Some change is also apparent in the working diffuser, principally in the longer wavelengths, where the reflectivity appears to have increased $\sim 0.3 \%$ over four years. The comparison to 
the lunar irradiance model generally appears to be good, though there is more scatter than relative to the lamps and diffusers. Work is currently underway on the lunar irradiance model in an attempt to reduce this scatter.

In the instrument itself, only the CA band shows any clear evidence of degradation. An initial exponential decay followed by an approximately linear with time degradation for a total change in responsivity of about $1.2 \%$ over four years.

\section{CONCLUSIONS}

The Landsat- 8 OLI instrument continues to be remarkably stable over its four years on orbit. Significant change is only apparent in the Coastal Aerosol band and this approximately $1 \%$ change in response is currently being corrected in operational data processing.

In addition, all the on-board calibration devices are working well, and with the exception of a few small $(<1 \%)$ degradations in the devices used most frequently, have not degraded. The availability of the multiple devices allows identifying the degrading devices and deciphering instrument change from calibrator change.

\section{REFERENCES}

[1] H.H. Kieffer and T.C. Stone, "The spectral irradiance of the Moon." Astron. J., 129, pp 2887-2901, 2009. 